\title{
Gloires et malheurs des théories du développement, Colin Leys, Jean-Philippe Peemans
}

Danielle de Lame

\section{(2) OpenEdition \\ Journals}

Édition électronique

URL : http://journals.openedition.org/apad/108

DOI : 10.4000/apad.108

ISSN : 1950-6929

Éditeur

LIT Verlag

Édition imprimée

Date de publication : 1 décembre 2001

\section{Référence électronique}

Danielle de Lame, «Gloires et malheurs des théories du développement, Colin Leys, Jean-Philippe

Peemans », Bulletin de l'APAD [En ligne], 22 | 2001, mis en ligne le 15 février 2006, consulté le 22

septembre 2020. URL : http://journals.openedition.org/apad/108 ; DOI : https://doi.org/10.4000/apad. 108

Ce document a été généré automatiquement le 22 septembre 2020.

Bulletin de l'APAD 


\title{
Gloires et malheurs des théories du développement, Colin Leys, Jean- Philippe Peemans
}

\author{
Danielle de Lame
}

1 The Rise and Fall of Development Theory est un classique d'une approche critique des théories du développement. Ce recueil, édité à cinq reprises entre 1977 et 1996 et chaque fois mis à jours en fonction des nouveaux avatars des théories et des politiques appliquées à l'Afrique, reste un manuel de base dense, critique et ancré dans le désir de voir se rejoindre les théories rénovées et les études des processus de développement.

2 L'ouvrage de Jean-Philippe Peemans, quant à lui, entend confronter "les théories du développement face aux histoires du développement réel dans la seconde moitié du XXème siècle". En réalité, ce second ouvrage, qui a l'avantage d'aborder les politiques de développement à l'échelle mondiale, reste assez éloigné des pratiques du développement et se cantonne dans une confrontation des théories aux idéologies des grandes instances internationales. Il s'agit d'un exemple brillant de maîtrise de la littérature qui est cependant moins systématiquement dépouillée à partir de 1995. L'auteur entend situer la pensée concernant le développement dans son contexte historique: "on ne peut comprendre le processus de formation de la pensée sur le développement ni la diversité de ses orientations que si on la resitue dans une périodisation qui correspond aux inflexions du contexte historique dans laquelle elle s'est déployée, et aux conflits d'acteurs qui ont marqué ces différentes périodes". "Il s'agit ... de situer les discours sur le développement et leurs avatars pratiques par rapport aux vicissitudes du 'développement réel'", à travers "une opposition entre l'ordre des choses et l'ordre des peuples et des gens". C'est à ce point que me semble apparaitre une double faiblesse d'un ouvrage par ailleurs fort riche, parce qu'il déborde l'Afrique et aborde aussi les pays d'Asie et d'Amérique latine. En effet, l'impression produite malgré, ou peut-être à cause, de la virtuosité verbale, est celle d'un discours d'ordre, plutôt que d'étude critique. L'insertion des théories dans l'histoire qui les a produites se fait au niveau de la macro-économie et non au niveau de ses effets sur les 
populations qui leur sont prétexte autant qu'elles en sont victimes, autant aussi, qu'elles en sont, à la marge, acteurs. La micro-économie locale de ce que l'auteur appelle "la farce humanitaire" des Grands-Lacs montrerait, en effet, des acteurs locaux, voire même nationaux, menant leur politique propre dans le contexte évoqué. A ce niveau de base, manque l'approche des processus de développement réel au sein desquels, pour rester dans cette note, les appropriations locales du mondial humanitaire rejoignent parfois le libéralisme le plus sauvage.

3 L'ouvrage de Colin Leys est plus critique et analyse les théories du développement à la lumière des circonstances de leur production. En limitant son ouvrage à l'Afrique, l'auteur opte, du même coup, pour une confrontation plus étroite des théories à des réalités qui, sans être homogènes, présentent des similarités quant à l'héritage colonial, au rôle de l'état ou aux modes de production et d'accumulation. Il montre aussi la marginalisation croissante de l'Afrique dans le contexte mondial. Ici, les théories, depuis celle de la modernisation jusqu'à celle du choix rationnel en passant par la théorie de la dépendance, sont confrontées aux réalités africaines. L'analyse de plusieurs cas vient à l'appui, notamment l'Uganda et le Kenya. Pour C. Leys, l'étude de la formation d'une bourgeoisie africaine et de ses stratégies est au cœur de l'étude du développement africain, mais la "tragédie africaine montre aussi clairement et de façon fort concrète que les théories du développement ne peuvent se limiter au Tiers Monde ou traiter le monde développé et ses options comme un "donné". Cette perspective le démarque de l'ouvrage de J.-Ph. Peemans dont l'érudition éloigne le lecteur de populations cibles qu'il ne parvient pas à percevoir comme des sociétés, des peuples possédant une autonomie et des modes de fonctionnement propres.

\section{BIBLIOGRAPHIE}

Leys C., 1996, The Rise and Fall of Development Theories, Nairobi, Bloomington, Oxford: EAEP, Indiana University Press, J. Currey

Peemans J.-Ph., 2002, Le développement des peuples face à la modernisation du monde. Essai sur les rapports entre l'évolution des théories du développement et les histoires du développement réel dans la seconde moitié du XXe siècle. Louvain-la-Neuve, Paris : Academia Bruylant, L'Harmattan. 